Ambiente e desenvolvimento 



\title{
Mudanças climáticas e desenvolvimento
}

\author{
JOSÉ GOLDEMBERG
}

$\mathrm{U}$

MA INDICAÇÃo que evidencia o progresso atingido por uma cidade ou região é a ausência de lixo nas ruas, a existência de esgotos, a água de boa qualidade e o ar puro. Estas são as características de muitas regiões desde a época do Império Romano e que caracterizam hoje as cidades dos países industrializados.

Por essa razão as preocupações com a qualidade do ar e da água, a destinação adequada do esgoto e do lixo, bem como a eliminação de resíduos tóxicos, dominaram a agenda ambiental até recentemente.

Mesmo países em desenvolvimento, onde um esforço considerável tem sido feito neste sentido, a ação das agências fiscalizadoras da qualidade ambiental - como a Cetesb - tem sido bastante eficaz.

Todos esses problemas ambientais, contudo, são de caráter locale as autoridades municipais - e às vezes estaduais - são responsáveis pelas medidas tomadas e arcam com seus custos de forma direta ou indireta. Se não houver interesse e empenho dessas autoridades as ações não serão implementadas. É inútil esperar-se que os habitantes dos países ricos paguem pela limpeza do ar de São Paulo ou das águas do rio Tietê, cuja poluição não os afeta. No máximo pode-se conseguir deles auxílios de caráter filantrópico - que são pequenos - ou empréstimos do Banco Mundial - que precisarão ser pagos.

Tal situação está mudando devido à emergência um tipo novo de problema ambiental que é a poluição global. Sucede que a emissão de gases, como dióxido de carbono (que é o resultado da combustão de carvão, petróleo e gás), está aumentando e mudando a composição da atmosfera. Esses gases, mesmo emitidos na China, circulam por toda atmosfera e, portanto, sua presença afeta não só os chineses mas também as populações dos países industrializados. O seu efeito é o de atuar como um cobertor que impede o calor de escapar da superfície terrestre para o espaço, fazendo a sua temperatura subir. É este fenômeno físico - o assim chamado efeito estufa - que explica por que o interior de um automóvel fica tão quente num dia ensolarado, mesmo no inverno (figura seguinte). 


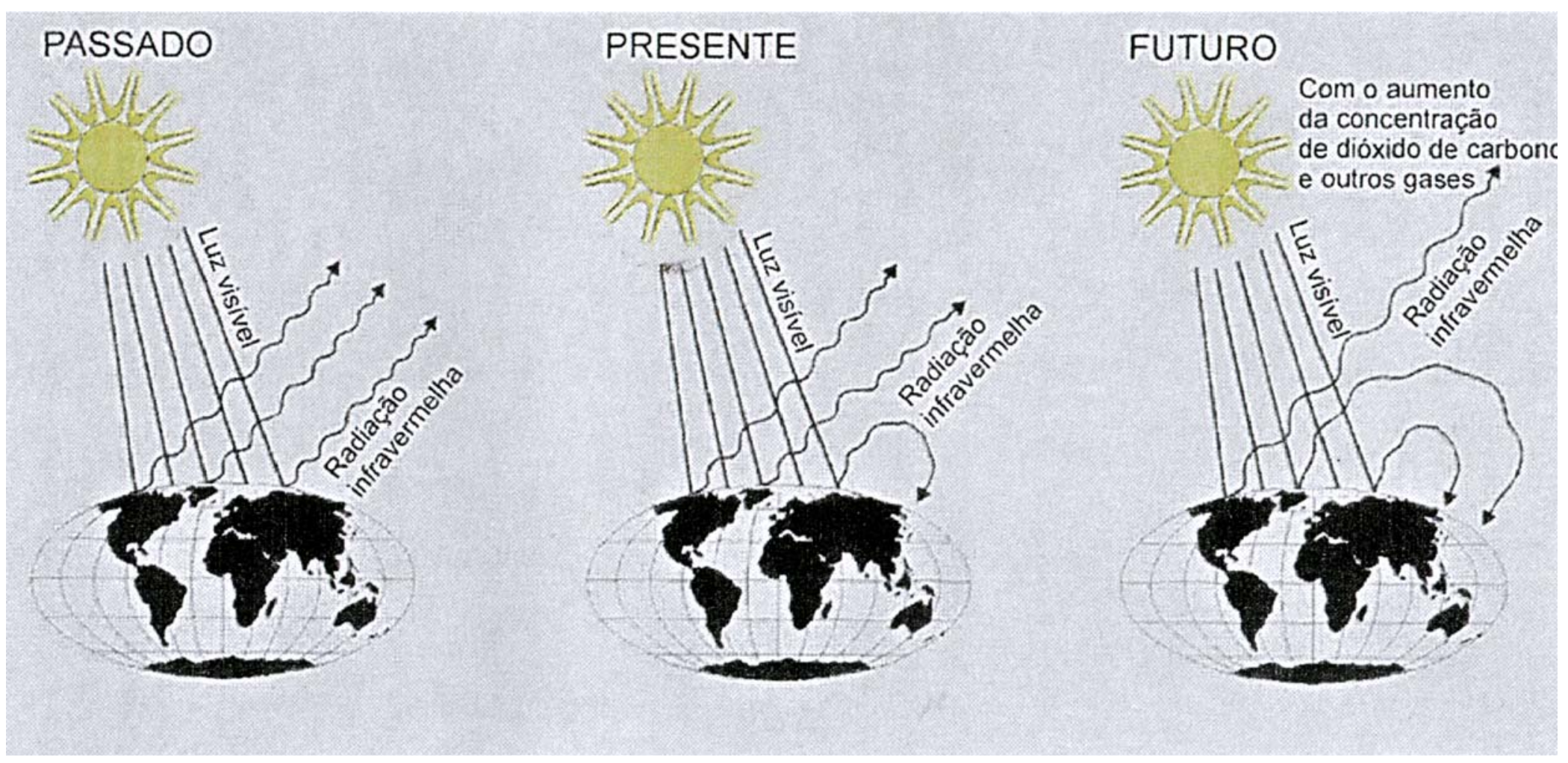

O efeito estufa 
O que ocorre é o seguinte: a atmosfera é transparente à luz solar e, assim, a radiação que vem do Sol (e torna nosso planeta habitável) atinge o solo sem problemas, onde é absorvida e reemetida sob a forma de calor. Sucede que a atmosfera é um isolante térmico e não deixa este calor escapar.

A atmosfera é um isolante térmico pela presença de uma pequena porcentagem de dióxido de carbono nela existente (cerca de 370 partes por milhão de volume). Sucede que essa porcentagem está aumentando porque um dos principais efeitos da ação humana no meio ambiente é queimar combustíveis fósseis e lançar dióxido de carbono na atmosfera. Desde o início da Revolução Industrial, cerca de 200 anos atrás, a quantidade deste gás na atmosfera já aumentou 30\%, acreditando-se que irá dobrar nos próximos 50 anos. Com isso, prevê-se que a temperatura da Terra deverá aumentar um ou dois graus centígrados, o que deverá bastar para causar grandes alterações no clima terrestre.

As atividades industriais do Brasil contribuem pouco para as emissões mundiais de carbono, mas a extensão do desmatamento na Amazônia - cerca de $15.000 \mathrm{~km}^{2}$ por ano - coloca o país entre os dez maiores emissores mundiais deste gás.

É por essa razão que em 1992, no Rio de Janeiro, foi adotada uma “Convenção sobre o Clima". De acordo com ela, os países industrializados deverão reduzir suas emissões de gases que provocam o efeito estufa, mas os países em desenvolvimento não estão sujeitos a tais limitações porque seu crescimento econômico exige maior consumo de combustíveis fósseis.

Os grandes emissores são os países industrializados, mas não vai ser fácil a esses países reduzir suas emissões. Por essa razão, o Protocolo de Kyoto, adotado em 1997 (mas ainda não ratificado), criou vários mecanismos chamados de mecanismo de flexilibização para conseguir reduzir as emissões do conjunto dos países industrializados em cerca de $5 \%$ abaixo do seu nível de emissão em 1990.

Estes mecanismos de flexibilização são os seguintes:

- troca de emissões

- implementação conjunta

- desenvolvimento limpo (CDM)

A troca de emissõesé um mecanismo baseado no mercado. Ele permite que reduções sejam obtidas pela utilização de diferenças no custo da diminuição de emissões em diferentes países, uma vez que gases responsáveis pelo efeito estufa se espalham uniformemente na atmosfera. Os prejuízos 
resultantes das emissões e os benefícios por suas reduções são independentes da sua origem. Reduções de emissões obtidas na Espanha, por exemplo, podem ser creditadas à Alemanha, onde elas teriam maiores custos ao serem realizadas. Essas trocas são autorizadas apenas entre países industrializados.

A implementação conjunta é outro mecanismo por meio do qual um país pode implementar um projeto que leve a reduções de emissões em outro país, contabilizando-as em sua quota, desde que arque com os custos do projeto. Um exemplo de implementação conjunta foi o que ocorreu entre o México e a Noruega, que pagou pela troca de lâmpadas incandescentes por outras mais eficientes no México, o que levou a reduções de emissões contabilizadas na quota da Noruega. O Protocolo de Kyoto restringiu esse mecanismo aos países industrializados e à troca realizada entre governos.

O desenvolvimento limpo é o terceiro mecanismo criado pelo Protocolo de Kyoto. De acordo com ele, os países industrializados terão de reduzir suas emissões em cerca de um bilhão de toneladas de carbono por ano, dentro de 10 anos. Tal procedimento será muito difícil de ser implementado por meio de medidas adotadas internamente, principalmente nos Estados Unidos. Projetos implementados em países em desenvolvimento, como o Brasil, poderão ser aceitos como uma das formas de cumprir o Protocolo, desde que redundem na redução das emissões de carbono. A novidade com relação ao mecanismo da implantação conjunta é que, além de entidades públicas, empresas poderão fazer as trocas diretamente entre si.

Não existe um exemplo melhor de projeto do tipo contemplado pelo mecanismo de desenvolvimento limpo do que a substituição de gasolina por álcool, produzido a partir da cana de açúcar, como é feito no Brasil. Álcool é um combustível renovável porque, ao ser queimado nos veículos que o usam, emite $\mathrm{CO}^{2}$ que é recapturado pela cana de açúcar ao crescer na safra seguinte.

Atualmente o Brasil estaria consumindo o dobro da gasolina que consome se o Programa do Álcool não existisse. Com a atual produção de cerca de 12 bilhões de litros de álcool por ano, o Brasil emite 10 milhões de toneladas de carbono a menos do que poderia estar emitindo; tal redução corresponde a $15 \%$ de todas as emissões de carbono do país.

Acredita-se que essas reduções de emissões terão um valor monetário de pelo menos US\$ 20 por tonelada de carbono, cuja emissão for evitada. Dessa forma, o Programa do Álcool deveria gerar US\$ 200 milhões por ano, sem qualquer outro esforço adicional, além de uma boa negociação diplomática. 
O exemplo citado do Programa do Álcool representa apenas uma das possibilidades para reduzir a emissão de carbono. Outras já foram identificadas, como o reflorestamento de áreas com florestas degradadas que compensariam inclusive o desmatamento da Amazônia, que o governo não tem tido condições de controlar.

Poder-se-ia argumentar que há outros problemas ambientais mais urgentes para serem resolvidos, como a qualidade do ar das grandes cidades como São Paulo, a poluição da baía de Guanabara, entre tantos, mas eles terão de ser enfrentados pelas autoridades locais sem grande auxilio do exterior, a não ser empréstimos de bancos internacionais para os quais existem muitas demandas.

A participação no mecanismo de desenvolvimento limpo poderá ser feita por entidades públicas ou privadas, isto é, também por empresas, como já mencionado.

Nem todos os projetos que impliquem redução das emissões de gases que provocam o efeito estufa serão elegíveis como objeto de transação mediante o mecanismo de desenvolvimento limpo, porque o Protocolo de Kyoto estabelece certos critérios gerais a serem cumpridos, especificamente:

- que redundem em reduções certificáveis e mensuráveis de gases que provocam o efeito estufa e

- que contribuam para o desenvolvimento sustentável.

Além disso, alguns projetos terão mais potencial de levar a reduções de emissões do que outros.

Uma interessante análise foi feita sobre o potencial que uma variedade de projetos teria para se qualificar e ser aceita pelo mecanismo de desenvolvimento limpo, conforme dados do quadro apresentado a seguir.

Um primeiro esforço para identificar, no Brasil, projetos que se qualificariam para o mecanismo de desenvolvimento limpo foi feito por um grupo da Universidade de São Paulo, em colaboração com a Universidade da Califórnia (Berkeley).

Neste esforço, duas categorias de projetos foram identificados:

- energia (11);

- sequestro de carbono (4).

$\mathrm{Na}$ categoria de energia, os projetos distribuíram-se da seguinte forma: 
- eficiência energética (2);

- energia renovável (8);

- cogeração (1).

Na categoria de seqüestro de carbono, os projetos eram:

- reflorestamento permanente (1);

- plantação de biomassa para outros usos (3).

Para acelerar todo o processo o BNDES poderia inicialmente comprar os certificados de reduções de emissões, o que faria com que certas empresas nacionais realizassem projetos sem esperar por aprovação internacional. Esses certificados poderiam ser vendidos mais tarde, no exterior, provavelmente com ágio elevado.

Quando o Protocolo de Kyoto for ratificado, o Brasil será um forte candidato a captar parte apreciável dos recursos a serem disponibilizados para cumprir as metas de redução dos países industrializados. Estima-se que a captação anual poderá ser de US\$ 3 bilhões. Tais recursos estarão associados a investimentos em tecnologias limpas e serão naturalmente um instrumento de modernização da economia brasileira.

José Goldemberg, físico, é professor honorário do Instituto de Estudos Avançados da Universidade de São Paulo. 
Comparação quanto ao pontecial de redução de gases que produzem efeito estufa com a utilização do mecanismo de desenvolvimento limpo entre diversos projetos

\begin{tabular}{|c|c|c|c|}
\hline Projetos & $\begin{array}{c}\text { Reduçסes } \\
\text { reais } \\
\text { mensuráveis } \\
\text { e certificáveis } \\
\end{array}$ & $\begin{array}{c}\text { Relevância } \\
\text { para } \\
\text { desenvolvimento } \\
\text { sustentável } \\
\end{array}$ & $\begin{array}{l}\text { Potencial de } \\
\text { reduçăo }\end{array}$ \\
\hline $\begin{array}{l}\text { Setor de Energia } \\
\text { - Substituição de combustíveis } \\
\text { - } \text { - Usseis por combustiveis limpos } \\
\text { - } \text { - Rembustiveicis fósseis } \\
\text { combura das emissões de } \\
\text { Processos industriais } \\
\text { - Aumento da eficiência de } \\
\text { produção } \\
\text { - Uso de materiais e processos } \\
\text { alternativos } \\
\text { Setor da agricultura } \\
\text { - Melhoria da alimentação de } \\
\text { animais } \\
\text { - Melhoria do gerenciamento } \\
\text { dos resíduos vegetais } \\
\text { - Modificação dos métodos de } \\
\text { cultivo de arroz } \\
\text { - Substituição de fertilizantes à } \\
\text { base de nitrogênio } \\
\text { - Eliminação de queima a céu } \\
\text { aberto de resíduos agricolas } \\
\text { Mudanças no uso solo e manejo } \\
\text { florestal } \\
\text { - Proteção e conservação de } \\
\text { florestas } \\
\text { - Melhoria da eficiência do } \\
\text { manejo florestal } \\
\text { - Reflorestamento e } \\
\text { regeneração de florestas } \\
\text { - Melhoria das práticas } \\
\text { agroflorestais } \\
\text { Residuos agrícolas } \\
\text { - Redução e reciclagem de } \\
\text { resíduos } \\
\text { - Captura do metano dos } \\
\text { resíduos } \\
\text { - Eliminação da queima a céu } \\
\text { aberto de resíduos }\end{array}$ & $\begin{array}{l}\mathrm{L} \\
\mathrm{L} \\
\mathrm{L} \\
\mathrm{L} \\
\mathrm{L}\end{array}$ & $\begin{array}{l}M \\
H \\
L \\
H \\
M\end{array}$ & $\begin{array}{c}\mathrm{L} \\
\mathrm{L} \\
\mathrm{H}-\mathrm{H} \\
\mathrm{L} \\
\mathrm{L}\end{array}$ \\
\hline
\end{tabular}

$\mathrm{H}=$ Alta probabilidade de satisfazer os critérios do Mecanismo de Desenvolvimento Limpo $\mathrm{M}=$ Média probabilidade de satisfazer os critérios do Mecanismo de Desenvolvimento Limpo $\mathrm{L}=$ Baixa probabilidade de satisfazer os critérios do Mecanismo de Desenvolvimento Limpo 